\title{
THE DIFFERENCE OF IoS AND ANDROID USAGE
}

\author{
By: \\ Rachel Margaretha Siburian ${ }^{1)}$ \\ Ripta Permata Nuary ${ }^{2)}$ \\ Indonesia Post Polytechnic, Bandung ${ }^{1,2)}$ \\ E-Mail: \\ rhel.margaretha16@gmail.com ${ }^{1)}$ \\ ripta.permata.nuary@gmail.com ${ }^{2)}$
}

\begin{abstract}
This research aims at comparing the quality, price, users and interest of the society on IoS and Android. This research also directs readers to be more careful in choosing a product, wiser in comparing products. Both of IoS and Android products are good enough but it would be nice to choose the better one. The reason for conducting this research is to facilitate consumers in choosing products. The method research used is qualitative with natural observers, and the use of questionnaires to obtain data from several communities in the Pos Indonesia Polytechnic Campus.
\end{abstract}

\section{Keywords: IoS, Android, Qualitative Research}

\section{PRELIMINARY}

In daily life it is known that technology interferes in human life. And today's technological developments play a very important role. An example is the use of mobile phones in daily life. Mobile phone is very important in people's life today. It is used as communication tool with other people. It makes people in far distance becomes closer. It makes people communicate with one another more easily. Today, mobile has many types, from ordinary mobile phones to very sophisticated ones. The examples are Android and IoS. 
Android and iOS (iPhone) are the two most popular operating systems among smartphone users, especially smartphone OS based on touch screens. Both of these operating systems continue competing for the market they are looking for. But it can be seen that android has more users that iPhone becauseiPhone is still quite expensive for the lower middle class.

The other reason why Android is used more than IoS is because Android and IoS have some differences and competitiveness that arevery visible. In this age, smartphones have different qualitieswhich become the consideration for users to choose the smartphones they want to use. Now it depends on the people's interest in owning a smartphone by considering the quality and not forgetting the price.

As it is known that the price of Android is cheaper compared to IoS. Sometimes it depends on the quality of each smartphone, because every smartphone that is issued / produced has their own function, price and quality. Many say that IoS is better than Android but sometimes the quality of IoS can be lower or vice versa.

The high class prefers the use of IoSin contrast to the lower classwho prefer to use Android because the price is affordable and not inferior to the quality of IoS. It is something common that if someone has already used an IoS smartphone, many people think that theycome from thehigh class. But it is not always true. Theymight only be the middle class who can afford to buy an IoS smartphone.

It can be seen from the samples taken at Indonesia Post Polytechnic Campus. The data taken from thirty (30) students in this campus shows that they prefer using Android instead of IoS, because according to them Android is easier to 
use and cheaper than IoS which is good, but the price is exorbitant.

\section{a. Formulation of the}

\section{Problem}

1. How is the quality of IoS compared to Android?

2. How is the interest of Indonesia Post Polytechnic students in using IoS and Android?

b. Formulation of the Hypothesis

1. Indonesia Post Polytechnic students are more interested inusing Android than IoS.

2. People consider that the quality of Android is not inferior to the quality of IoS.

3. The upper class students in Indonesia Post Polytechnic Campusare more interested in using IoS than on Android.

\section{IMPLEMENTATION}

The method used in this study is natural observations or qualitative methods with associative hypotheses. In this study, the object of research was the Public Interest of Indonesia Post Polytechnic studentsin the use of IoS or Android

The research was conducted at Indonesia Post Polytechnic Campus. Data retrieval was done with questionnaires given to Indonesia Post Polytechnic students. The population for the study was taken from the first level students of Indonesia Post Polytechnic. Thirty (30) samples were taken using accidental sampling method. The questionnaire used was a multiple choice system with the choice of answers strongly disagree, disagree, agreeand strongly agree. Analysis was carried out to describe the respondent's character based on questionnaire date.

\section{Discussion}


In daily life it is known that technology interferes in human life. And today's technological developments play a very important role. An example is the use of mobile phones in daily life. Mobile phone is very important in people's life today. It is used as communication tool with other people. It makes people in far distance becomes closer. It makes people communicate with one another more easily. Today, mobile has many types, from ordinary mobile phones to very sophisticated ones. The examples are Android and IoS.

Android and iOS (iPhone) are the two most popular operating systems among smartphone users, especially smartphone OS based on touch screens. Both of these operating systems continue competing for the market they are looking for. But it can be seen that android has more users that iPhone because iPhone is still quite expensive for the lower middle class.

The other reason why Android is used more than IoS is because Android and IoS have some differences and competitiveness that are very visible. In this age, smartphones have different qualities which become the consideration for users to choose the smartphones they want to use. Now it depends on the people's interest in owning a smartphone by considering the quality and not forgetting the price.

As it is known that the price of Android is cheaper compared to IoS. Sometimes it depends on the quality of each smartphone, because every smartphone that is issued / produced has their own function, price and quality. Many say that $\operatorname{IoS}$ is better than Android but sometimes the quality of IoS can be lower or vice versa.

The high class prefers the use of IoS in contrast to the lower class who 
prefer to use Android because the price is affordable and not inferior to the quality of IoS. It is something common that if someone has already used an IoS smartphone, many people think that they come from the high class. But it is not always true. They might only be the middle class who can afford to buy an IoS smartphone.

It can be seen from the samples taken at Indonesia Post Polytechnic Campus. The data taken from thirty (30) students in this campus shows that they prefer using Android instead of IoS, because according to them Android is easier to use and cheaper than IoS which is good, but the price is exorbitant.

\section{Conclusions}

And

\section{Recommendations}

\section{Conclusions}

The conclusion of the study is that Android and IoS are equally good in quality, but the price of IoS is more expensive than Android even though sometimes the quality can be the same. IoS users at Indonesia Post Polytechnic are not too many, it might be caused by the high price or it might also because they do not intend to use the Smartphone. Android is the most popular smartphone at Indonesia Post Polytechnic. The result are concluded from the questionnaires made and distributed by the writer.

\section{Recommendation}

From this research it can be known the current state of technology. According to this study, the interest of IoS or Android users is driven by the quality and price set on the product. It is recommended that products such as IoS or Android be further developed, and understand the existing marketing.

\section{REFERENCE}

1. https://idcloudhost.com/fakta-danperbedaan-seputar-android-dan$\underline{\text { ios/ }}$ 
2. https://www.diffen.com/differenc

e/Android_vs_iOS
3. https://id.wikipedia.org/wiki/Siste

m_operasi_telepon_genggam 